\title{
Comparison of Reproducibility of Nasolabial Angle Constructed bu Anatomic point method and Tangent line method
}

\author{
Dr Jamal Giri,, Dr Prabhat Ranjan Pokharel,2 Dr Rajesh Gyawali,3 \\ Dr Bhushan Bhattarai,4 Dr Gunjan Kumar Shrestha ${ }^{5}$ \\ 13Asst Prof, ${ }^{2}$ Assoc Prof, Dept of Orthodontics, BP Koirala Institute of Health Sciences, Dharan \\ ${ }^{4}$ Lecturer, Dept of Orthodontics, Nobel Medical College, Biratnagar \\ sLecturer, Dept of Orthodontics, MB Kedia Dental College, Birgunj, Nepal
}

Correspondence: Dr Jamal Giri; Email: nepalipilot@gmail.com

\section{ABSTRACT}

Introduction: Investigators have drawn nasolabial angle using different soft tissue landmarks. This has created confusion among the orthodontic students and clinicians regarding its construction.

Objective: To evaluate two commonly used methods of constructing the nasolabial angle in order to establish a single reproducible method.

Materials \& Method: Lateral cephalograms of 120 patients undergoing orthodontic treatment were obtained from the records of the patients. Soft tissue profile on the lateral cephalograms were traced manually by the principal investigator. All the tracings were photocopied and 6 copies of each tracing were made. Nasolabial angles were constructed and measured on photocopied copies of the tracings first using the anatomic point method and then using the tangent line method by the principal investigator and another investigator independently.

Result: The average nasolabial angle values for anatomic point method and tangent line method were found to be $94.32^{\circ} \pm$ $14.05^{\circ}$ and $92.4^{\circ} \pm 14.59^{\circ}$ respectively. The intra-class correlation coefficient demonstrated excellent intra-observer and interobserver agreement among the two methods of nasolabial angle construction.

Conclusion: Both anatomic point method and tangent line method of nasolabial angle construction have excellent reproducibility in terms of intra-observer and inter-observer agreement.

Key-words: anatomic point method, lateral cephalogram, nasolabial angle, tangent line method

\section{INTRODUCTION}

Traditionally, orthodontic diagnosis and treatment planning was based on hard tissue relationship of jaws and dentition. However, there has been a paradigm shift towards soft tissue-based orthodontic diagnosis and treatment planning. The primary goal of orthodontic treatment is to achieve the ideal soft tissue profile. This emerging soft tissue paradigm places greater emphasis on clinical examination of soft tissue function and esthetics than has previously been the case.' Even though there are various soft tissue diagnostic parameters, nasolabial angle is considered a dependable representative of the soft tissue profile and a clinical and cephalometric parameter to establish the treatment goals. ${ }^{2,3}$

Nasolabial angle, the angle formed between the lower border of the nose and the upper lip, is an important parameter in orthodontic diagnosis and treatment planning. ${ }^{4}$ The angle is an indicator of relative position of maxilla, maxillary dentition and nose. Decision of extraction or non-extraction during orthodontic treatment is also influenced by nasolabial angle. ${ }^{5}$

Lack of universal definition of nasolabial angle has led to variability in construction of nasolabial angle. Over the years, various investigators ${ }^{6-9}$ have drawn the nasolabial angle using different soft tissue landmarks. This has created confusion among the orthodontic students and clinicians alike regarding the construction of nasolabial angle. An improperly constructed nasolabial angle can adversely affect orthodontic diagnosis and treatment planning..$^{10}$ Till date, there are no studies in orthodontic literature comparing the reproducibility of different methods of construction of nasolabial angle. Hence, the primary objective of this study was to evaluate two commonly used methods of construction of the nasolabial angle, namely anatomic point method and tangent line method, in order to establish a single reproducible method. The secondary objective was to assess whether the two methods of construction would lead to significant difference in the values of the angle. 


\section{MATERIALS AND METHOD}

Pre-treatment lateral cephalograms of one hundred and twenty patients (55 males and 65 females) who were undergoing orthodontic treatment in the Department of Orthodontics, BP Koirala Institute of Health Sciences (BPKIHS), Dharan were obtained from the records of the patients. Lateral cephalograms of the patients with lip and nose deformities were excluded from the study. Ethical clearance was obtained from the Institutional Review Committee of BPKIHS before conducting the study.

Soft tissue profile on the lateral cephalogram was traced manually on 0.003 inch matte acetate paper using sharp $3 \mathrm{H}$ drawing pencil by the principal investigator (JG) and verified by another investigator (PRP) for all lateral cephalograms. All the tracings were photocopied and six copies of each tracing were made: two each for anatomic point method and tangent line method of nasolabial angle construction for the principal investigator and one each for anatomic point method and tangent line method of nasolabial angle construction for another investigator (RG).
Nasolabial angles were constructed on photocopied tracing first using the anatomic point method and then using the tangent line method separately by the principal investigator. Another investigator (RG) also constructed these angles using both methods independently (Figure 1). Landmarks given by Park and Burstone ${ }^{7}$ were used for the construction of nasolabial angle in anatomic point method (Figure 2). Similarly, Scheideman and coworkers' method $^{6}$ was used to construct nasolabial angle using tangent lines (Figure 3). Then the angles were measured and the values were recorded by both the investigators independently. Additionally, the nasolabial angles were reconstructed and measured by the principal investigator after 2 weeks of initial measurement.

SPSS software version 11 was used for data analysis. Intraclass correlation coefficient (ICC) was calculated to assess the intra-observer and inter-observer reproducibility. Independent samples T-test was used to compare the mean values of nasolabial angle obtained by two construction methods.

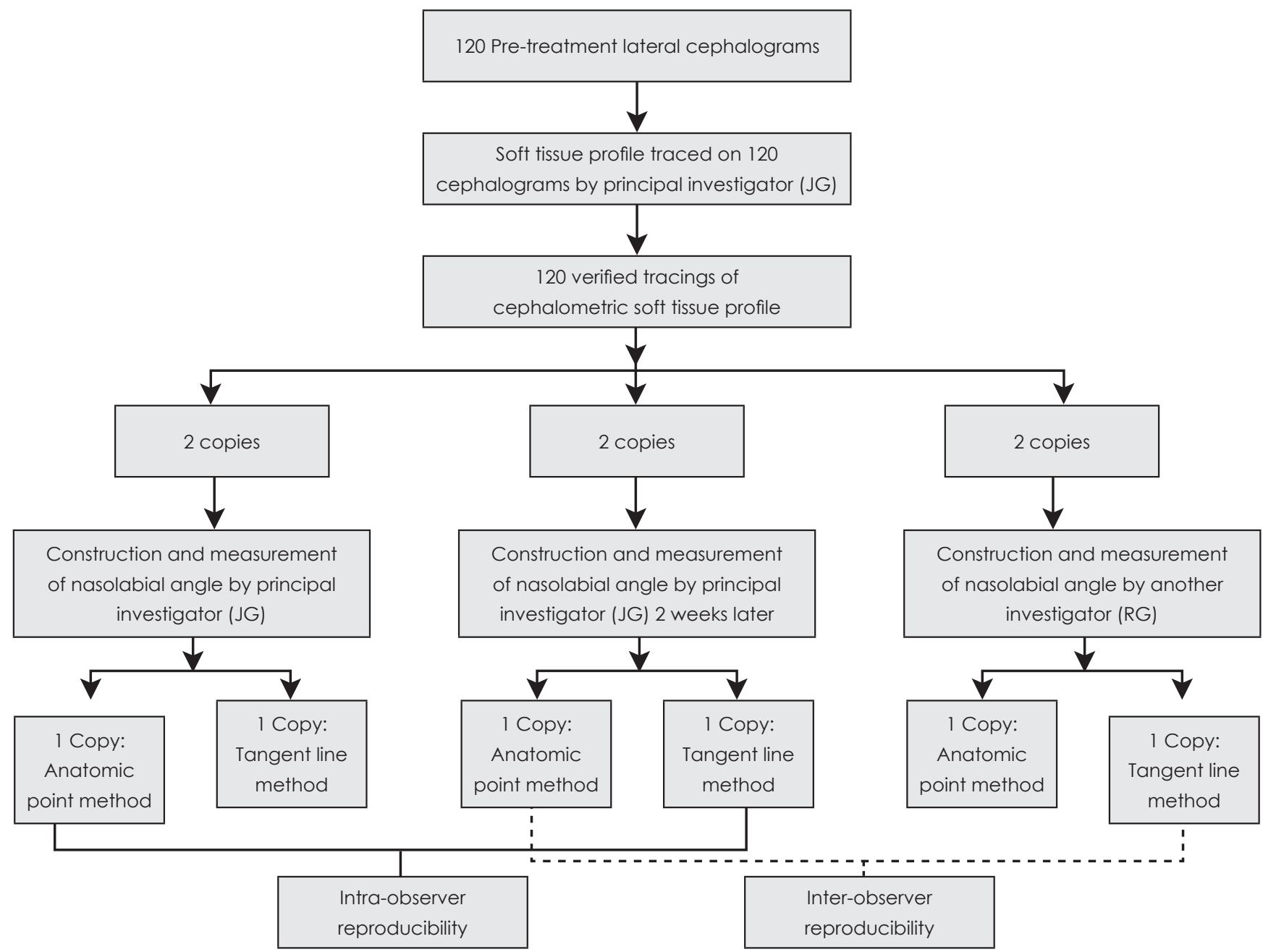

Figure 1: Flow diagram depicting the methodology used 


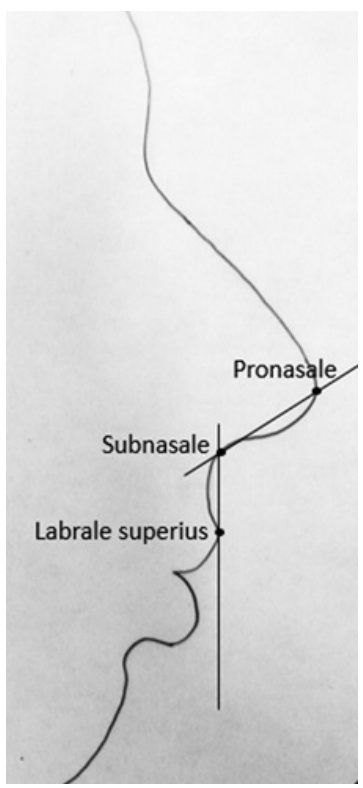

Figure 2: Anatomic point method of construction of nasolabial angle

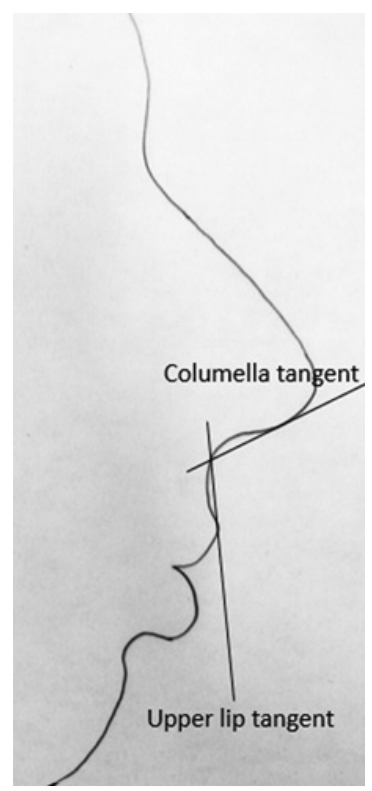

Figure 3: Tangent line method of construction of nasolabial angle

\section{RESULT}

The mean age of the samples was $21.11 \pm 3.57$ years. Likewise, the average nasolabial angle values for anatomic point method and tangent line method were found to be $94.32^{\circ} \pm$ $14.05^{\circ}$ and $92.4^{\circ} \pm 14.59^{\circ}$ respectively. This difference was not statistically significant. The intra-class correlation coefficient (ICC) demonstrated excellent intra-observer and interobserver agreement among the two methods of nasolabial angle construction (Table 1,2).

\section{DISCUSSION}

Achievement of esthetically pleasing and balanced face is the primary goal of soft tissue driven orthodontic treatment." However, accurate quantification of soft tissue profile on lateral cephalogram is a cumbersome task because soft tissue profile is made up of numerous curved lines which have to be converted into straight lines for measuring angles. This process of transforming curves into straight lines could vary with person and time making it less reproducible. ${ }^{12}$ The nasolabial angle is no exception. This angle is formed by two straight lines in the nasolabial region of soft tissue profile, one from the columella of the nose and the other from the upper lip. ${ }^{13}$ These two lines can be constructed using anatomic landmarks or by drawing tangents to the soft tissue contours of nose and upper lip.

Cephalometric analysis which is used for orthodontic diagnosis and treatment planning is not foolproof. Human errors can creep which may jeopardise the accuracy, reproducibility and even validity of the cephalometric measurements. ${ }^{14} \mathrm{So}$ in an attempt to minimize errors, 6 copies of original tracing were made using photocopy machine instead of tracing each of
Table 1: Intra-observer agreement for anatomic point and tangent line methods of nasolabial angle construction

\begin{tabular}{|l|c|c|}
\hline \multicolumn{1}{|c|}{ Method used } & ICC value & $\begin{array}{c}\text { Strength of } \\
\text { agreement }\end{array}$ \\
\hline Anatomic point method & 0.986 & Excellent \\
\hline Tangent line method & 0.992 & Excellent \\
\hline
\end{tabular}

Table 2: Inter-observer agreement for anatomic point and tangent line methods of nasolabial angle construction

\begin{tabular}{|l|c|c|}
\hline \multicolumn{1}{|c|}{ Method used } & ICC value & $\begin{array}{c}\text { Strength of } \\
\text { agreement }\end{array}$ \\
\hline Anatomic point method & 0.998 & Excellent \\
\hline Tangent line method & 0.882 & Excellent \\
\hline
\end{tabular}

them. Also, hand tracing was preferred over digital tracing even though studies have shown no clinically significant difference between the two methods because hand tracing is all-time gold standard. ${ }^{15,16}$

In reviewing the literature, no study was found which compared the reproducibility of nasolabial angle construction by anatomic point method and tangent line method alone. However, two studies were found which assessed the reproducibility of angular measurements of soft tissue profile with nasolabial angle as one of the components using the two methods. ${ }^{12,17}$

This study found excellent inter-observer reproducibilities of the anatomic point method and tangent line method of nasolabial angle construction. However, these findings are in contrary to the findings of $\mathrm{Garg}^{17}$ and Hwang et $\mathrm{al}^{12}$ who have reported greater interobserver reproducibility with anatomic point method of nasolabial angle construction. This discrepancy in results could be attributed to differences in methods of drawing tangent lines for nasolabial angle construction. This study used the method described by Scheideman et $a^{16}$ whereas Garg ${ }^{17}$ and Hwang et al $^{12}$ had followed the method given by McNamara et al. ${ }^{18}$ It is possible to hypothesise that the method of Scheideman et al ${ }^{6}$ has greater reproducibility than McNamara et al. ${ }^{18}$ However, a further study with more focus on tangent line method of nasolabial angle construction is needed to validate this hypothesis.

This study also demonstrated excellent intra-observer reproducibilities of the anatomic point method and tangent line method of nasolabial angle construction when assessed within 2 weeks of initial construction and measurement in 120 lateral cephalograms. These findings are in agreement with Garg's findings ${ }^{17}$ which showed no advantage of anatomic point method over tangent line method as far as intra-observer reproducibility was concerned. It is somewhat surprising given that the Garg's study ${ }^{17}$ had shown poor interobserver reproducibility of tangent line method. The reason 
for this is not clear but it may have something to do with small sample size of just 40 samples. In contrary, Hwang et al ${ }^{12}$ reported greater intra-observer reproducibility with anatomic point method of nasolabial angle construction over tangent line method.

The mean difference between the nasolabial angle values constructed using anatomic point method and tangent line method was $1.92^{\circ}$. This was found to be statistically insignificant. Furthermore, any cephalometric measurement difference less than $2^{\circ}$ is considered clinically insignificant. ${ }^{19}$ It can thus be suggested that either of the two methods could be used for cephalometric analysis. However, it would be prudent to specify the method of nasolabial angle construction along with its value in orthodontic practice.

\section{CONCLUSION}

Both anatomic point method and tangent line method of nasolabial angle construction have excellent reproducibility in terms of intra-observer and inter-observer agreement. Also, there is no significant difference between the average values of the nasolabial angle constructed by the two methods. Hence, either of the two methods can be used for nasolabial angle construction during cephalometric soft tissue analysis.

\section{OJN}

\section{REFERENCES}

1. Sarver DM. Interactions of hard tissues, soft tissues, and growth over time, and their impact on orthodontic diagnosis and treatment planning. Am J Orthod Dentofac Orthop. 2015; 148(3):380-6.

2. Sinno HH, Markarian MK, Ibrahim AM, Lin SJ. The ideal nasolabial angle in rhinoplasty: A preference analysis of the general population. Plastic \& Reconstructive Surgery. 2014; 134(2):201-10.

3. Dua V, Gupta S, Singh C. Evaluation of the nasolabial angle in the Indian population. Contemp Clin Dent. $2010 ; 1$ (2):79-82.

4. Naini FB, Cobourne MT, McDonald F, Wertheim D. The aesthetic impact of upper lip inclination in orthodontics and orthognathic surgery. Eur J Orthod. 2015; 37(1):81-6.

5. Arnett GW, Bergman RT. Facial keys to orthodontic diagnosis and treatment planning--Part II. Am J Orthod Dentofac Orthop. 1993; 103(5):395-411.

6. Scheideman GB, Bell WH, Legan HL, Finn RA, Reisch JS. Cephalometric analysis of dentofacial normals. Am J Orthod. 1980; 78(4):404-20.

7. Park YC, Burstone CJ. Soft-tissue profile--fallacies of hard-tissue standards in treatment planning. Am J Orthod Dentofac Orthop. 1986; $90(1): 52-62$.

8. Fitzgerald JP, Nanda RS, Currier GF. An evaluation of the nasolabial angle and the relative inclinations of the nose and upper lip. Am J Orthod Dentofac Orthop. 1992; 102(4):328-34.

9. Magnani MB, Nover DF, Nover PR, Pereira Neto JS, Garbui IU, Boeck EM. Assessment of the nasolabial angle in young Brazilian black subjects with normal occlusion. Braz Oral Res. 2004; 18(3):233-7.

10. Nandini S, Prashanth CS, Somiah SK, Reddy SR. An evaluation of nasolabial angle and the relative inclinations of the nose and upper lip. J Contemp Dent Pract. 2011; 12(3):152-7.

11. Holdaway RA. A soft-tissue cephalometric analysis and its use in orthodontic treatment planning. Part I. Am J Orthod. 1983; 84(1):1-28.

12. Hwang HS, Kim WS, MCNamara JA, Jr. A comparative study of two methods of quantifying the soft tissue profile. Angle Orthod. 2000; 70(3):200-7.

13. Kandhasamy K, Prabu NM, Sivanmalai S, Prabu PS, Philip A, Chiramel JC. Evaluation of the nasolabial angle of the Komarapalayam population. J Pharma Bioallied Sci. 2012; 4(Suppl 2):S313-5.

14. Damstra J, Huddleston Slater JJ, Fourie Z, Ren Y. Reliability and the smallest detectable differences of lateral cephalometric measurements. Am J Orthod Dentofac Orthop. 2010; 138(5):541-8.

15. HujaSS, Grubaugh EL, Rummel AM, Fields HW, Beck FM. Comparison of hand-traced and computer-based cephalometric superimpositions. Angle Orthod. 2009; 79(3):428-5.

16. Prabhakar R, Rajakumar P, Karthikeyan MK, Saravanan R, Vikram NR, Reddy A. A hard tissue cephalometric comparative study between hand tracing and computerized tracing. J Pharma Bioallied Sci. 2014; 6(Suppl 1):S101-6.

17. Garg AK. How reliable are soft tissue cephalometric measurements: A reality check. Ind J Dent Sci. $2012 ; 4(5): 4$.

18. McNamara JA, Jr. A method of cephalometric evaluation. Am J Orthod. 1984; 86(6):449-69.

19. Gregston MD, Kula T, Hardman P, Glaros A, Kula K. A comparison of conventional and digital radiographic methods and cephalometric analysis software: I. hard tissue. Sem Orthod. 2004; 10(3):8. 